\title{
CORRECTION
}

\section{Correction to: Metallurgical and Tribological Evaluation of Fe-Cr-C Hardfacing Alloys}

Sachin Pawar - Goutam Mukhopadhyay • Aman Kumar Jha

Published online: 21 May 2018

(C) ASM International 2018

Correction to: J Fail. Anal. and Preven.

https://doi.org/10.1007/s11668-018-0475-8

In the original article, Aman Kumar Jha was inadvertently omitted as a co-author.

The original article can be found online at https://doi.org/10.1007/ s11668-018-0475-8.

S. Pawar $(\bowtie) \cdot$ G. Mukhopadhyay

R\&D and Scientific Services, Tata Steel, Jamshedpur 831001,

India

e-mail: sachinpawar@tatasteel.com

A. K. Jha

National Institute of Technology, Rourkela, India 